BioScience Trends. 2020; 14(3):E2.

DOI: $10.5582 /$ bst.2020.E2

\title{
RETRACTED: Polyphosphate-induced matrix metalloproteinase-3-mediated proliferation in rat dental pulp fibroblast-like cells is mediated by a Wnt5 signaling cascade.
}

This article entitled "Polyphosphate-induced matrix metalloproteinase-3-mediated proliferation in rat dental pulp fibroblast-like cells is mediated by a Wnt5 signaling cascade" (1) has been retracted at the request of the authors due to research misconduct.

Reference

1. Ozeki N, Yamaguchi H, Hase N, Hiyama T, Kawai R, Kondo A, Nakata K, Mogi M. Polyphosphate-induced matrix metalloproteinase-3-mediated proliferation in rat dental pulp fibroblast-like cells is mediated by a Wnt5 signaling cascade. Biosci Trends. 2015; 9(3):160-168. DOI: 10.5582/ bst.2015.01041. 